\title{
Reference intervals for 26 common biochemical analytes in term neonates in Jilin Province, China
}

\author{
Kaijin Wang ${ }^{1}$, Xuetong Zhu', Qi Zhou² and Jiancheng $X u^{1 *}$
}

\begin{abstract}
Background: Biochemical analytes provide information for neonatal disease management and therapy, and populationbased reference intervals (RIs) are essential to accurately interpret laboratory test results. This study aimed to establish local Rls for biochemical assays in term neonates.

Methods: A total of 195 healthy term neonates from birth to 3rd day were recruited as reference individuals prospectively. Analytes of 26 common biochemistries were measured using the VITROS 5600 Integrated System. The 3-level nested ANOVA was performed to assess the need for partitioning Rls of each analyte, and Rls were derived by a nonparametric method or robust method. Multiple regression analysis was used to evaluate specific correlations between the analytes and individual characteristics including age, gender, gestational age, birthweight and delivery mode.

Results: There were no between-sex differences in all analytes, whereas there were significant between-day-age differences in 6 analytes. Small between-delivery-mode differences were observed in the results for potassium, phosphorus, and urea. The major related factor of most analytes was postnatal age. During the first 3 days, values of iron, lipids and lipoproteins increased; creatinine, urea, uric acid, creatine kinase and lactate dehydrogenase decreased; other analytes showed slight changes or relatively stable trends. Reference limits of some analytes, particularly lactate dehydrogenase and alkaline phosphatase, were significantly different from adult and pediatric groups.

Conclusions: Rls of 26 common biochemical analytes are established for term neonates aged 0 to 3 days in northeast China. Additionally, it is suggested that age-related changes should be valued in the clinical decision-making process for newborns.
\end{abstract}

Keywords: Biochemical analytes, Neonates, Reference intervals, Enzymes, Lipids

\section{Introduction}

Reference intervals (RIs) are determined from individuals in healthy status, serving as tools for interpreting laboratory results. Despite the well standardized measurements of major laboratory tests, it is difficult to establish harmonized and uniform RIs on a global scale. Previous research has found that the differences in RIs of analytes are due to

\footnotetext{
* Correspondence: xjc@jlu.edu.cn

'Department of Laboratory Medicine, First Hospital of Jilin University, Changchun, China

Full list of author information is available at the end of the article
}

their complex patterns of biological sources of variations, such as region, race, diet, and other individual characteristics $[1,2]$. Data from several studies suggest that age- and sex-specific RIs are more reliable to provide clinical decision support in the pediatric population [3-5]. Moreover, differences in analytical systems and statistical procedures may result in the differences between RIs reported in different studies [6-9]. Every aspect should be considered during the determination of accurate RIs.

Recently, there has been renewed interest in neonatal RIs with increased attention to neonatal health screening

(c) The Author(s). 2021 Open Access This article is licensed under a Creative Commons Attribution 4.0 International License, which permits use, sharing, adaptation, distribution and reproduction in any medium or format, as long as you give appropriate credit to the original author(s) and the source, provide a link to the Creative Commons licence, and indicate if changes were made. The images or other third party material in this article are included in the article's Creative Commons licence, unless indicated otherwise in a credit line to the material. If material is not included in the article's Creative Commons licence and your intended use is not permitted by statutory regulation or exceeds the permitted use, you will need to obtain permission directly from the copyright holder. To view a copy of this licence, visit http://creativecommons.org/licenses/by/4.0/. The Creative Commons Public Domain Dedication waiver (http://creativecommons.org/publicdomain/zero/1.0/) applies to the data made available in this article, unless otherwise stated in a credit line to the data. 
and management [10, 11]. Anthropometry and laboratory data are useful for neonatal growth and nutrition assessment [12]. The common biochemical analytes are related to measuring the functional maturity of organ systems, monitoring the changes of electrolyte and acidbase status, and evaluating the ability of material absorption and metabolism. Hence they can not only help diagnose relevant diseases but also engage in pharmacokinetic research. The Ministry of Health P. R. China has published several industry standards which provide RIs for common clinical biochemistry and immunology tests in adults, while data about newborns are not available. A few recent studies have established neonatal RIs for biochemistry analytes based on the local population, preterm and low-birth-weight infants included [11, 13-15]. However, most clinical laboratories in China adopt RIs from textbooks, reagent inserts, or adult reference standards. These data might be obsolete, lack of any traceability, or established on mismatched population in race or age, and then would be misleading to interpretate laboratory results. Thus, this study aimed to investigate the RIs for newborns during the first days in Jilin Province, China.

The Clinical and Laboratory Standards Institute (CLSI) recommends a priori method to determine RIs, namely selecting healthy individuals defined by specific reference criteria as reference populations in advance [16]. Another commonly used method, posteriori selection process, is to establish RIs using a large clinical database. There is difficulty in retrospectively establishing RIs in newborns for lack of a precise definition. The criteria may differ between different analytes, and neonates are prone to complicated pathological conditions during hospitalization. However, recruitment of healthy infants is also difficult because of ethical constraints for collecting unnecessary blood samples. We conducted this research with written informed consent from parents, and the specimen collection procedure was evaluated by qualified pediatricians to ensure rationality and applicability in local medical practice.

It is now widely acknowledged that term infants are different from preterm infants in the measured values of most biochemistry analytes [17-19]. Meanwhile, the two groups of infants have quite different causes of hospitalization. The premature are more susceptible to severe diseases for their immature organ function; whereas the common reasons for term infants to be hospitalized are birth injury, feeding intolerance, jaundice, sepsis and other medical complications. With this background, doctors should choose rational sets of tests and assess the results according to different criteria. In addition, most studies focus on establishing RIs and analyzing the correlations between individual parameters and analytes in newborns, who are born preterm or admitted to the neonatal intensive care unit. However, detailed data about term infants is limited.

Therefore, this prospective study aimed to determine RIs of 26 common biochemical analytes for term newborns during the first 3 days, and investigate the associations between the analytes and neonatal characteristics.

\section{Materials and methods}

\section{Ethics}

This study was approved by the Ethics Committee of the First Hospital of Jilin University, and written informed consent was obtained from all the babies' parents.

\section{Study participants}

Recruitment of subjects was from the obstetric unit of the First Hospital of Jilin University between July 2018 and October 2018, with 195 healthy term neonates enrolled prospectively. Neonatal assessment was performed by neonatal physicians, and maternal medical records were also reviewed. Eligibility criteria included gestational age between 37 and 42 weeks, birthweight $\geq 2500 \mathrm{~g}$ and $<4000 \mathrm{~g}$, Apgar score at 1 and $5 \mathrm{~min} \geq 7$, and the newborn was delivered by normal delivery or elective caesarean section. Infants were excluded from this study if they had congenital infections, chromosomal abnormalities or severe neonatal diseases diagnosed in the perinatal period, as well as infants of mothers suffering from hypertension, thyroid dysfunction or other severe illnesses. All newborns were routinely vaccinated with hepatitis B and Bacillus Calmette-Guérin (BCG) after birth, and given vitamin K1 $1 \mathrm{mg}$ intramuscularly.

\section{Sample collection and laboratory procedure}

Serum samples of newborns were taken within the first 3 days of life after obtaining informed consent from parents. A $4 \mathrm{ml}$ sample of blood was collected into serum separation tubes in the morning from radial artery using a disposable butterfly needle. The samples were transported to the laboratory and centrifuged at $1200 \times \mathrm{g}$ for $10 \mathrm{~min}$ within $1 \mathrm{~h}$ after collection. Specimens that were icteric, hemolyzed, or lipemic were removed prior to analysis, and then the activity or concentration of 26 biochemical analytes were determined on the VITROS 5600 Integrated System (Ortho Clinical Diagnostics/ Johnson \& Johnson, Raritan, NJ, USA) within $2 \mathrm{~h}$ after separation. The analytes were as follows: total carbon dioxide $\left(\mathrm{CO}_{2}\right)$, chloride $(\mathrm{Cl})$, potassium $(\mathrm{K})$, sodium $(\mathrm{Na})$, calcium $(\mathrm{Ca})$, iron $(\mathrm{Fe})$, magnesium $(\mathrm{Mg})$, phosphorus $(\mathrm{P})$, creatinine $(\mathrm{Cr})$, urea $(\mathrm{BUN})$, uric acid (UA), alanine aminotransferase (ALT), alkaline phosphatase (ALP), aspartate aminotransferase (AST), cholinesterase (CHE), creatine kinase (CK), creatine kinase MB form (CK-MB), gamma glutamyl transferase (GGT), lactate dehydrogenase (LDH), albumin (Alb), total protein (TP), transferrin 
iron-binding capacity (TIBC), cholesterol (TCHO), highdensity lipoprotein-cholesterol (HDL-C) and triglycerides (TG). The low-density lipoprotein-cholesterol (LDL-C) result was calculated with the Friedewald equation for SI units [LDL-C = TC $-\mathrm{HDL}-\mathrm{C}-(\mathrm{TG} / 2.2)]$. All reagents and quality control products for the assays were purchased from Ortho Clinical Diagnostics/ Johnson \& Johnson company. Qualified laboratory proficiency and staff training were described in the research conducted in the same period $[6,8]$. Analytical procedures were performed according to the manufacturer's instructions and laboratory protocols, including regular maintenance, function checks, calibration, and internal quality control. Details of analytical methods and performance were listed in Supplemental Table 1.

\section{Statistical analysis}

The study population was divided into subgroups according to delivery mode, sex and day age. Histogram and Shapiro-Wilk test were performed to detect data distribution before statistical analysis, and non-normal data was logarithmically transformed. Demographic data were expressed as mean \pm standard deviation or number when appropriate. Mann-Whitney test or Wilcoxon rank sum test was used to compare numerical variables; Chi-square test was used for categorical variables.

For all the biochemical analytes, outliers were eliminated using the Dixon D/R ratio rule first, and data were expressed as median and interquartile range. Percentile curves were generated for all analytes using the vector generalized linear and additive models (vgam package) $[20,21]$ with the LMS Quantile Regression function. Three-level nested ANOVA was applied to evaluate sources of variation of RIs [22]. The magnitude of between-subgroup differences partitioned by the factors was computed as the standard deviation (SD) ratio (SDR), which corresponded to the SD from betweensubgroup variation divided by SD between individuals. The variations of between-delivery-mode, between-sex and between-day-age components were expressed as SDR-dm, SDR-sex and SDR-age respectively. A ratio greater than 0.40 was considered as the criterion to partition RIs, in order to reduce bias caused by a narrow measure of between-individual variation $[1,23]$. According to CLSI EP28-A3C guidelines [16], the lower limits (LL) and upper limits (UL), referring to 2.5 th percentiles and 97.5 th percentiles, were derived by the nonparametric method or robust method after deciding the partition. The 90\% confidence intervals (CIs) for reference limits were estimated on the bootstrap method through iterative resampling 1000 times.

Multiple linear regression was used to investigate the associations between the analytes and individual characteristics, including GA, birthweight, delivery mode, sex and postnatal age. The significance of each variable was evaluated as standard partial regression coefficient $\left(r_{p}\right)$, which corresponded to partial correlation coefficient and takes value between -1.0 and 1.0. Based on an objective classification system in previous studies [24, 25], the practical correlation was characterized as slight for $0.20 \leq\left|r_{p}\right|<0.30$, moderate for $0.30 \leq\left|r_{p}\right|<0.50$ and strong for $0.50 \geq\left|r_{p}\right|$. All statistical analyses were performed using the $R$ statistic software (version 3.6.0) and MedCalc Software (version 15.2). A bilateral $P$-value < 0.05 indicated statistical significance.

\section{Results}

\section{Characteristics of study participants}

A total of 195 term infants with postnatal age of 1-3 days fulfilled the inclusion criteria, and demographic information was shown in Table 1. Overall, both sexes were approximately equally represented in the study population, whereas the percentage of babies by caesarean section and on the second day was relatively large, accounting for 86.7 and $61.5 \%$ respectively. In brief, sex, birthweight, gestational age, maternal age and delivery mode did not show significant differences among the day-age groups.

\section{Trends and RI establishment for common biochemical analytes}

The division of RIs was codetermined by the scatter plot and 3-level nested ANOVA. Twenty-six common biochemical analytes had been measured during the first 3 days of life, and variation tendency depicted with the smoothed percentile curves for all analytes. Figure 1 and supplement Figures presented some interesting patterns, 1) BUN, Cr and UA significantly decreased over time, whereas $\mathrm{Fe}$ increased gradually within the 3 days; 2) there was an overall slight decrease in AST, CK, GGT, $\mathrm{LDH}, \mathrm{CK}-\mathrm{MB}, \mathrm{CO}_{2}$ and TIBC, while ALP showed a minor increase; 3) during the first day of life, Alb, TP, $\mathrm{CHE}$ and $\mathrm{K}$ decreased slightly, whereas $\mathrm{Cl}$ and $\mathrm{Na}$ increased slightly, and then they held steady in the following days; 4) TCHO, HDL-C, LDL-C and TG seemed to be steady during the first 2 days and began to rise on the 3rd day; 5) Ca appeared to decline within 2 days and then leveled off, yet $\mathrm{Mg}$ and $\mathrm{P}$ represented an opposite trend; 6) ALT remained steady all the time.

By adopting 0.40 as a significant effect size for SDR, the result of 3-level nested ANOVA showed that none of the analytes was affected by sex. The SDR values for delivery mode (SDR-dm) were higher than 0.40 for $\mathrm{K}, \mathrm{P}$ and BUN. As shown in Fig. 2, the upper limit (UL) and lower limit (LL) of subgroups divided by delivery mode were similar for BUN; instead, the BUN decreased significantly in a time-dependent manner. In this case, the RI of BUN was not partitioned by the mode of delivery. 
Table 1 Participant demographics

\begin{tabular}{|c|c|c|c|c|c|}
\hline \multirow[t]{2}{*}{ Characteristics } & \multirow{2}{*}{$\begin{array}{l}\text { Total } \\
n=195\end{array}$} & \multirow{2}{*}{$\begin{array}{l}\text { Day } 1 \\
n=21\end{array}$} & \multirow{2}{*}{$\begin{array}{l}\text { Day } 2 \\
n=120\end{array}$} & \multirow{2}{*}{$\begin{array}{l}\text { Day } 3 \\
n=54\end{array}$} & \multirow{2}{*}{$\begin{array}{l}P \\
\text { value }\end{array}$} \\
\hline & & & & & \\
\hline Gestational age (weeks) & $38.7 \pm 1.1$ & $39.0 \pm 0.86$ & $38.6 \pm 1.1$ & $38.7 \pm 1.1$ & 0.17 \\
\hline Birthweight (kg) & $3.37 \pm 0.43$ & $3.58 \pm 0.44$ & $3.33 \pm 0.45$ & $3.37 \pm 0.39$ & 0.13 \\
\hline Boys/girls & $104 / 91$ & $12 / 9$ & $62 / 58$ & $30 / 24$ & 0.83 \\
\hline Vaginal delivery/caesarean section & $26 / 169$ & $5 / 16$ & $14 / 106$ & $7 / 47$ & 0.31 \\
\hline
\end{tabular}

Data represented as mean \pm standard deviation or number when appropriate

When the RIs of $\mathrm{K}$ and $\mathrm{P}$ were analyzed for vaginal births (VD) and cesarean-section (C/S) groups respectively, the UL of VD group (RI: $3.2-5.9 \mathrm{mmol} / \mathrm{L}$ ) for $\mathrm{K}$ was higher than that of C/S group (RI: $3.3-5.4 \mathrm{mmol} / \mathrm{L}$ ); the LL of VD group (RI: $1.56-2.79 \mathrm{mmol} / \mathrm{L}$ ) for $\mathrm{P}$ was lower than that of C/S group (RI: $1.78-2.77 \mathrm{mmol} / \mathrm{L}$ ). A small numerical distance was acceptable according to the clinician's recommendation and the level of clinical decision limit for both, the combined RIs of $\mathrm{K}$ and $\mathrm{P}$ were calculated to be $3.3-5.4 \mathrm{mmol} / \mathrm{L}$ and $1.70-2.75 \mathrm{mmol} / \mathrm{L}$.

From Table 2, the differences among day-age groups expressed as SDR-age were highlighted for 6 analytes. The medians and ULs of Fe, TCHO and TG gradually increased with age, however the changes of LLs were not very noticeable; the RIs for renal function tests (BUN, Cr and UA) went an apparent decline (Fig. 1). Age-specific RI for each analyte was summarized in Table 3.

\section{MRA to evaluate the correlations between individual characteristics and biochemical analytes}

Multiple linear regression analysis (MRA) in Table 4 showed consistent results with nested ANOVA analysis. For newborns, there was no actually significant association between sex and analyte concentrations during perinatal period. Instead, age was the main source of variation related to most analytes. In the regression models, some analytes showed slight associations with the delivery mode, birthweight and gestational age $\left(\left|r_{p}\right|<\right.$ $0.3)$. Infants born by vaginal delivery had a slightly high level of K and BUN and a slightly low level of P, compared to cesarean delivery. For BW-related changes, birthweight was positively correlated with $\mathrm{P}$ and TIBC and negatively correlated with ALT and ALP; for GArelated changes, GA showed positive correlations with ALT, CK and TP.

\section{Rls comparison to other studies}

The RIs of the 26 biochemical analytes showed differences among this study, reagent inserts and other published data (see Fig. 3 and Supplemental Table 2). Comparing with the adult RIs provided by manufacturers, $\mathrm{Cl}, \mathrm{K}, \mathrm{Na}$, and $\mathrm{Mg}$ did not show significant differences; lower ULs and LLs for $\mathrm{CO}_{2}, \mathrm{Ca}, \mathrm{Fe}, \mathrm{TIBC}, \mathrm{BUN}$, Cr, UA, ALT, CHE, Alb and TP were observed in healthy neonates, however higher values for P, ALP, AST, GGT, CK, LDH could be seen. In particular, the analysis of CK-MB, lipid or lipoprotein was complex in adults, therefore direct comparisons of the RIs were omitted.

In comparison with the RIs derived from other experimental designs, sex partitions were not emphasized in all the researches, but different age divisions and reference limits were able to be observed. These results showed that some differences in LDH were quite marked among the RIs listed for similar age groups. ULs of $\mathrm{Ca}, \mathrm{Mg}, \mathrm{Fe}, \mathrm{TCHO}$ and HDL-C are significantly lower than those from the experiment based on the cord blood in Korean [13]. The RIs of most analytes are similar to those from the study in Lanzhou, China [15], however the RIs of liver enzymes except CHE showed great differences compared with those from Zhengzhou, China [26].

\section{Discussion}

This study described the distribution and dynamic changes of biochemistry analytes from healthy term infants during the first 3 days of life in northeast China. There was heterogeneity in analytes with different biological sources of variations, however, day age showed a predominant correlation with the concentration for most analytes. Premature and term infants were prone to different diseases, and the demand for clinical evaluation and nursing intervention varied [27]. Therefore, the local RIs in term infants were derived for ensuring a high accuracy of clinical management.

\section{Age-dependent Rls for $\mathbf{2 6}$ common biochemical analytes}

In reviewing the literature, gestational age and birthweight were regarded as key factors for establishing RIs for preterm infants, but little difference of the two factors would be found in healthy term newborns. Although the guidance documents for establishing RIs only set the lowest limit for the number of subgroup participants, there was no single, specific definition for age intervals. If the age intervals were too wide, the rapid changes in a short time might be otherwise overlooked. Therefore, this study statistically depended upon SDR$\mathrm{dm}$, SDR-sex and SDR-age to analyze differences 

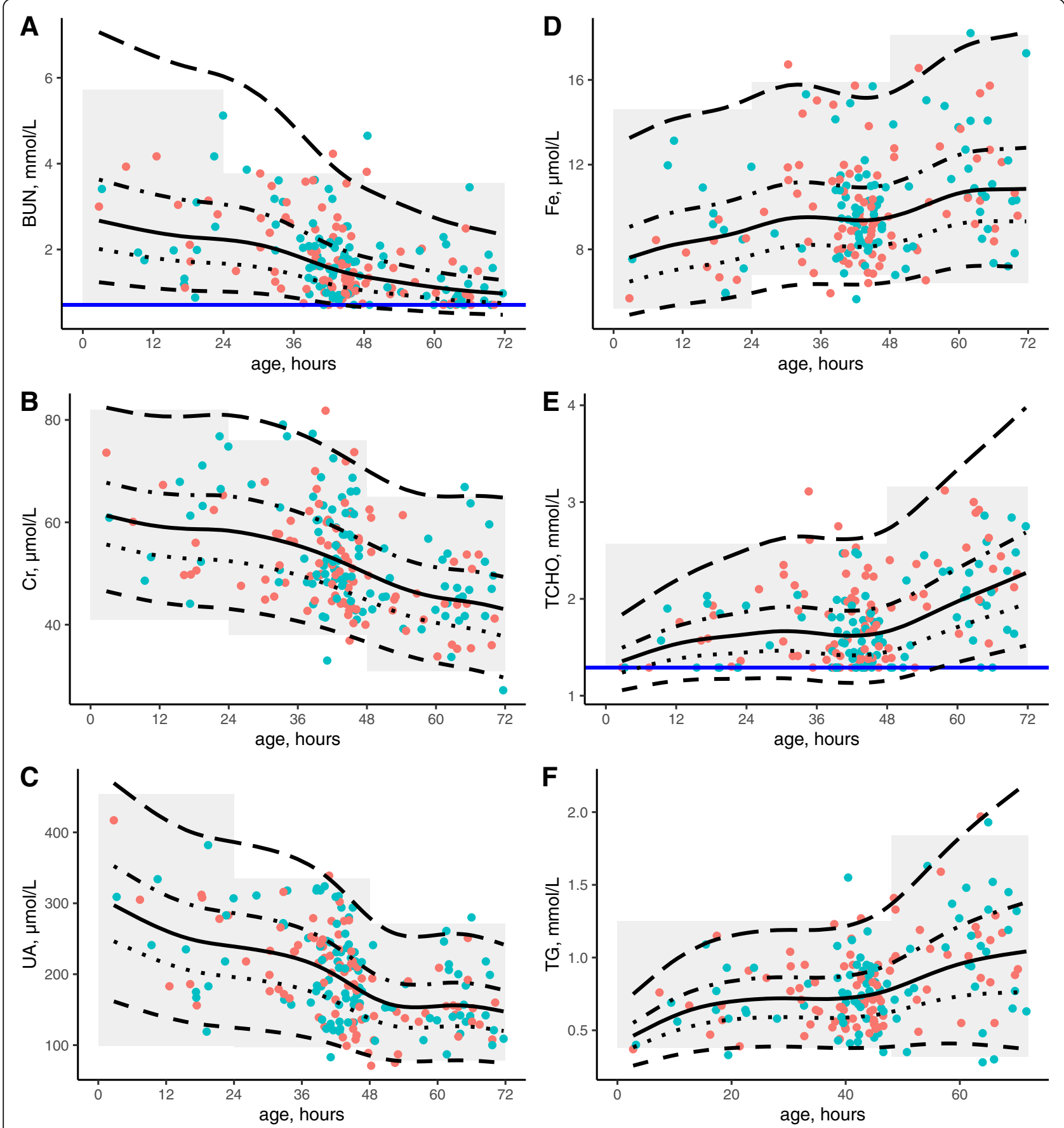

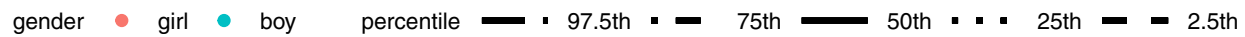

Fig. 1 Percentile charts and partitioned RIs for BUN, Cr, UA, Fe, TCHO and TG. The Rls are indicated in grey area. Horizontal blue lines shown in the graphs for $\mathrm{BUN}$ and $\mathrm{TCHO}$ represent lowest detection limit

between subgroups, and then judged whether it was appropriate for clinical practice to partition RIs according to delivery mode, sex and postnatal age. Regarding the test results of SDR-dm and SDR-sex, RIs of all items did not require specific partitions (SDR $<0.40$ ) except for $K$,
$\mathrm{P}$ and BUN. It was suggested that the combination of scatter plots and SDR values decide whether to partition RIs for test results compared across different groups. This helps avoid exaggerated SDR for the actual narrow range of RIs or masked differences caused by the 


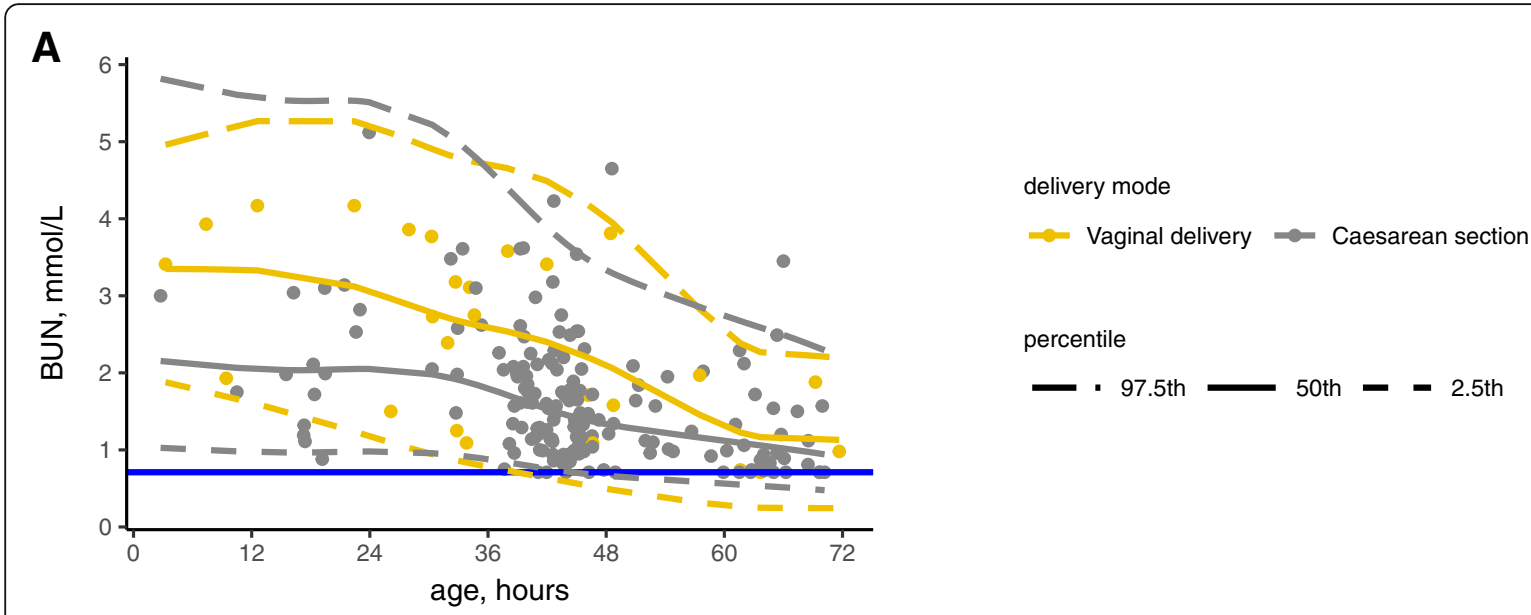

B

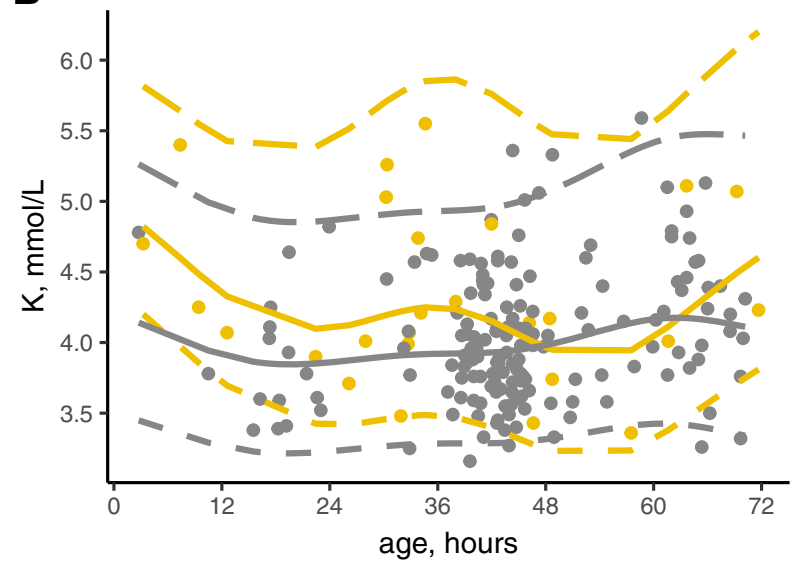

C

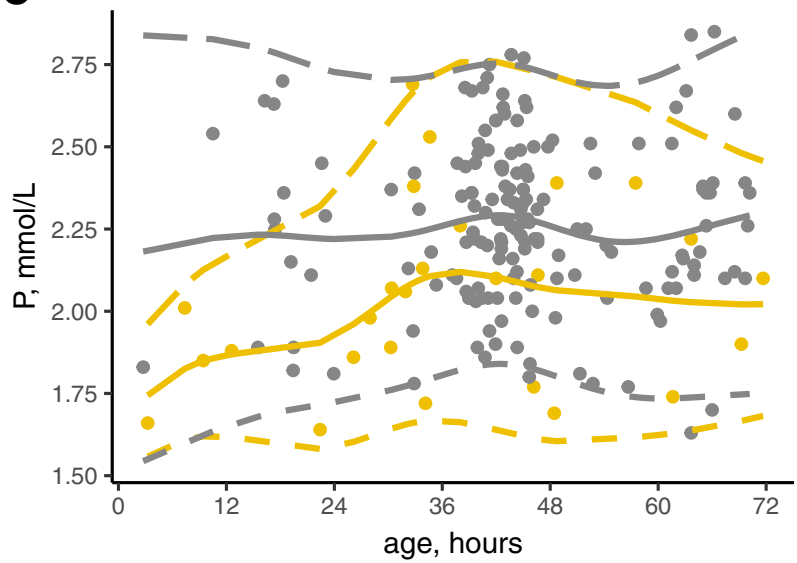

Fig. 2 Percentile charts for K, P and BUN between subgroups in different delivery modes. Horizontal blue lines shown in the graphs for BUN represent lowest detection limit

interaction between the factors [2, 28]. In effect, no sex difference for all analytes was detected, which was consistent with data in different regions $[5,11,13]$.

However, there were some considerable differences in postnatal age. This might be due to the rapid physiological adaptation to extrauterine life for newborns. A possible explanation for this might be that perinatal data was mainly affected by maternal and neonatal physiological factors during the first days of life. The concentration of each analyte reflected the balance between production, metabolism and clearance. First, some easyto-understand mechanisms may cause short-term fluctuations of most analytes, such as proteins, electrolytes, lipids [29] and renal function markers [30], listed as follows: 1) the exchange of substances based on placental transfer between the fetus and mother ceased abruptly after delivery; 2) developmental and maturational changes occurred in the organs during the perinatal period, especially liver and kidney; 3 ) the intake of external nutrients directly and indirectly affected the concentration of metabolites. Furthermore, the stress response during labour can also have an impact. Enzyme levels evaluated in our study were consistent with Lackmann et al. who found that the cytoplasmic and mitochondrial enzymes presented similar activity curves, whereas the membrane-bound enzymes showed the opposite. The differences in enzymes were considered the result of minor cell damage caused by physiological hypoxia during labour [31]. However, the changes in our study may be not obvious enough because the release of enzymes was also affected by uterine contractions and physical stress through the birth canal, while the small number of natural delivery were included [32]. The regulation of substances by hormones was equally important after birth, which can be demonstrated by bone metabolism status in neonates. In addition to maternal vitamin $\mathrm{D}$ during pregnancy [33], serum $\mathrm{Ca}, \mathrm{Mg}$ and $\mathrm{P}$ homeostasis was also regulated by foetal parathyroid hormone (PTH), calcitriol, calcitonin, calcium sensing receptor (CaSR) and fibroblast growth factor-23 (FGF-23), which affecting bone physiology, intestinal absorption and renal excretion [34]. 
Table 2 Result of 3-level Nested ANOVA and summary of statistical description for 26 biochemical analytes according to day age

\begin{tabular}{|c|c|c|c|c|c|c|c|c|c|c|c|}
\hline \multirow[t]{2}{*}{ Analytes } & \multicolumn{3}{|c|}{ 3-level Nested ANOVA } & \multicolumn{2}{|l|}{ Day 1} & \multicolumn{2}{|l|}{ Day 2} & \multicolumn{2}{|l|}{ Day 3} & \multicolumn{2}{|l|}{ Total } \\
\hline & SDR-dm & SDR-sex & SDR-age & median & IQR & median & IQR & median & IQR & median & IQR \\
\hline $\mathrm{CO}_{2}, \mathrm{mmol} / \mathrm{L}$ & 0.221 & 0.000 & 0.100 & 24 & $22-25$ & 21 & $20-23$ & 21 & $19-25$ & 22 & $20-24$ \\
\hline $\mathrm{Cl}, \mathrm{mmol} / \mathrm{L}$ & 0.222 & 0.000 & 0.319 & 101 & $95-104$ & 103 & $100-104$ & 102 & $97-105$ & 102 & $98-104$ \\
\hline $\mathrm{K}, \mathrm{mmol} / \mathrm{L}$ & 0.431 & 0.000 & 0.231 & 3.9 & $3.6-4.3$ & 4.0 & $3.7-4.3$ & 4.2 & $3.8-4.5$ & 4.0 & $3.7-4.4$ \\
\hline $\mathrm{Na}, \mathrm{mmol} / \mathrm{L}$ & 0.000 & 0.000 & 0.021 & 135 & 133-136 & 135 & 133-137 & 135 & 133-136 & 135 & 133-137 \\
\hline $\mathrm{Ca}, \mathrm{mmol} / \mathrm{L}$ & 0.285 & 0.000 & 0.000 & 1.97 & $1.88-2.01$ & 1.92 & $1.83-2.03$ & 1.96 & $1.81-2.04$ & 1.95 & $1.83-2.03$ \\
\hline $\mathrm{Mg}, \mathrm{mmol} / \mathrm{L}$ & 0.264 & 0.000 & 0.323 & 0.77 & $0.76-0.80$ & 0.80 & $0.76-0.84$ & 0.80 & $0.78-0.87$ & 0.80 & $0.76-0.84$ \\
\hline $\mathrm{P}, \mathrm{mmol} / \mathrm{L}$ & 0.673 & 0.139 & 0.091 & 2.11 & $1.85-2.36$ & 2.28 & $2.10-2.43$ & 2.18 & $2.07-2.39$ & 2.25 & $2.07-2.42$ \\
\hline $\mathrm{Fe}, \mu \mathrm{mol} / \mathrm{L}$ & 0.151 & 0.000 & 0.411 & 8.4 & 7.1-9.4 & 9.4 & $8.3-11.0$ & 10.6 & $8.7-12.8$ & 9.6 & $8.3-11.3$ \\
\hline $\mathrm{TIBC}, \mu \mathrm{mol} / \mathrm{L}$ & 0.278 & 0.000 & 0.000 & 42.0 & $40.0-44.4$ & 40.4 & $37.8-43.0$ & 39.9 & $37.2-43.7$ & 40.5 & $37.7-43.3$ \\
\hline $\mathrm{BUN}, \mathrm{mmol} / \mathrm{L}$ & 0.580 & 0.000 & 0.519 & 2.53 & $1.75-3.14$ & 1.65 & $1.14-2.25$ & 1.08 & $0.78-1.63$ & 1.57 & $1.05-2.15$ \\
\hline $\mathrm{Cr}, \mu \mathrm{mol} / \mathrm{L}$ & 0.121 & 0.000 & 0.670 & 61 & $52-67$ & 52 & $48-60$ & 46 & $42-52$ & 51 & $45-60$ \\
\hline UA, $\mu \mathrm{mol} / \mathrm{L}$ & 0.000 & 0.000 & 0.675 & 278 & 183-308 & 209 & $164-244$ & 146 & 130-189 & 186 & $145-241$ \\
\hline$A L T, U / L$ & 0.164 & 0.000 & 0.000 & 30 & $27-32$ & 30 & $22-35$ & 31 & $25-34$ & 30 & $24-34$ \\
\hline$A L P, U / L$ & 0.096 & 0.228 & 0.000 & 143 & 129-155 & 150 & 123-167 & 156 & $141-172$ & 151 & $127-168$ \\
\hline AST, U/L & 0.000 & 0.272 & 0.180 & 56 & $52-83$ & 52 & $44-63$ & 52 & $42-63$ & 53 & $44-63$ \\
\hline $\mathrm{CHE}, \mathrm{U} / \mathrm{L}$ & 0.325 & 0.000 & 0.167 & 4326 & $4060-4983$ & 4266 & $3871-4696$ & 4272 & $4069-4458$ & 4279 & $3897-4655$ \\
\hline GGT, U/L & 0.000 & 0.000 & 0.000 & 133 & $91-169$ & 129 & 86-169 & 113 & $88-142$ & 122 & $86-169$ \\
\hline$C K, U / L$ & 0.000 & 0.213 & 0.251 & 412 & $297-470$ & 318 & $233-414$ & 238 & 157-382 & 304 & 203-415 \\
\hline CK-MB, U/L & 0.066 & 0.116 & 0.000 & 22 & $18-26$ & 24 & $18-30$ & 22 & $18-29$ & 23 & $18-30$ \\
\hline $\mathrm{LDH}, \mathrm{U} / \mathrm{L}$ & 0.000 & 0.146 & 0.246 & 1247 & $972-1330$ & 1149 & $1022-1270$ & 1039 & $928-1230$ & 1120 & $985-1285$ \\
\hline Alb, g/L & 0.263 & 0.215 & 0.116 & 33.7 & $30.8-36.3$ & 32.7 & $30.8-34.3$ & 32.3 & $30.3-34.7$ & 32.7 & $30.7-34.7$ \\
\hline $\mathrm{TP}, \mathrm{g} / \mathrm{L}$ & 0.314 & 0.190 & 0.000 & 47.1 & $45.6-50.8$ & 48.0 & $45.5-52.0$ & 49.6 & $45.6-52.2$ & 48.2 & $45.5-52.1$ \\
\hline $\mathrm{HDL}-\mathrm{C}, \mathrm{mmol} / \mathrm{L}$ & 0.117 & 0.000 & 0.315 & 0.62 & $0.55-0.80$ & 0.67 & $0.58-0.81$ & 0.71 & $0.59-0.83$ & 0.68 & $0.58-0.82$ \\
\hline $\mathrm{LDL}-\mathrm{C}, \mathrm{mmol} / \mathrm{L}$ & 0.000 & 0.000 & 0.319 & 0.56 & $0.51-0.80$ & 0.57 & $0.45-0.80$ & 0.90 & $0.56-1.15$ & 0.63 & $0.48-0.91$ \\
\hline $\mathrm{TCHO}, \mathrm{mmol} / \mathrm{L}$ & 0.125 & 0.000 & 0.618 & 1.57 & $1.29-1.85$ & 1.60 & $1.38-1.92$ & 2.08 & $1.65-2.39$ & 1.73 & $1.39-2.05$ \\
\hline $\mathrm{TG}, \mathrm{mmol} / \mathrm{L}$ & 0.000 & 0.000 & 0.517 & 0.64 & $0.56-0.77$ & 0.70 & $0.58-0.86$ & 1.02 & $0.77-1.26$ & 0.74 & $0.58-0.95$ \\
\hline
\end{tabular}

$\mathrm{SDR} \geq 0.4$ was used as a criterion for partition of reference values

$S D R$ standard deviation ratio, SDR-dm SDR for between-delivery-mode differences, SDR-sex SDR for between-sex differences, SDR-age SDR for between-day-age differences, $I Q R$, interquartile range

Other variables that related to RIs of biochemical analytes Generally the main considerations for sources of variations of each test were sex, age and BMI in adults and children, besides races and regions. In the case of neonates, even more factors came into play, including maternal and infant health, delivery mode, gestational age and weight at birth. The comparison between the MLA model and the nested ANOVA method indicated that the results of delivery mode and sex were almost the same in present study, and postnatal age was the main influence on the concentration of most analytes. Birthweight and gestational age were widely used in evaluating neonatal clinical outcomes, while both had limited effects on a few items. A possible explanation for this might be that the premature or overdue babies and the low birthweight or fetal macrosmia were not included in this study.
In this study, there was poor negative correlation between birthweight and ALT and ALP, but positive correlation with $\mathrm{P}$ and TIBC although in term healthy newborns. Surprisingly, the small but consistent inverse associations of birthweight with ALT and ALP remained in late adolescent [35] and adult [36]. In fact, an elevated level of ALT within the normal range was proven to predict the hepatic steatosis of metabolic syndrome [36, 37]. It may be assumed that birthweight is a proxy for exposures such as intrauterine nutrition or genetic factors that directly affect the liver. In addition, the opposite correlation of birthweight with ALP and P may reflect the inverse association between birthweight and bone strength. For another, the observed increasing levels in CK, TP and ALT with GA could be attributed to the rate of the babies' muscular mass, or to the development 
Table 3 Age-dependent reference intervals for 26 biochemical analytes in newborns

\begin{tabular}{|c|c|c|c|}
\hline Analytes & Age & Lower Limit $(90 \% \mathrm{Cl})$ & Upper Limit $(90 \% \mathrm{Cl})$ \\
\hline \multicolumn{4}{|l|}{ Chemistry } \\
\hline $\mathrm{CO}_{2}, \mathrm{mmol} / \mathrm{L}$ & $1-3 d$ & $16(16-17)$ & $28(28-29)$ \\
\hline $\mathrm{Cl}, \mathrm{mmol} / \mathrm{L}$ & $1-3 d$ & $92(91-93)$ & $108(108-109)$ \\
\hline $\mathrm{K}, \mathrm{mmol} / \mathrm{L}$ & $1-3 d$ & $3.3(3.2-3.4)$ & $5.4(5.1-5.6)$ \\
\hline $\mathrm{Na}, \mathrm{mmol} / \mathrm{L}$ & $1-3 d$ & $131(130-131)$ & $140(140-141)$ \\
\hline $\mathrm{Ca}, \mathrm{mmol} / \mathrm{L}$ & $1-3 d$ & $1.53(1.42-1.61)$ & $2.15(2.12-2.16)$ \\
\hline $\mathrm{Mg}, \mathrm{mmol} / \mathrm{L}$ & $1-3 d$ & $0.68(0.65-0.70)$ & $0.94(0.91-0.96)$ \\
\hline $\mathrm{P}, \mathrm{mmol} / \mathrm{L}$ & $1-3 d$ & $1.70(1.64-1.78)$ & $2.75(2.68-2.84)$ \\
\hline \multirow[t]{3}{*}{$\mathrm{Fe}, \mu \mathrm{mol} / \mathrm{L}$} & $1 d$ & $5.2(4.6-5.9)$ & $14.6(12.1-17.2)$ \\
\hline & $2 d$ & $6.8(6.6-7.0)$ & $15.9(14.6-17.4)$ \\
\hline & $3 d$ & $6.4(5.9-7.1)$ & $18.1(16.3-19.8)$ \\
\hline $\mathrm{TIBC}, \mu \mathrm{mol} / \mathrm{L}$ & $1-3 d$ & $32.9(31.9-35.1)$ & $52.4(50.5-55.5)$ \\
\hline \multirow[t]{3}{*}{$\mathrm{BUN}, \mathrm{mmol} / \mathrm{L}$} & $1 d$ & $0.71^{\mathrm{a}}$ & $5.72(4.58-6.87)$ \\
\hline & $2 d$ & $0.71^{\mathrm{a}}$ & $3.77(3.58-4.23)$ \\
\hline & $3 d$ & $0.71^{\mathrm{a}}$ & $3.55(2.56-5.04)$ \\
\hline \multirow[t]{3}{*}{$\mathrm{Cr}, \mu \mathrm{mol} / \mathrm{L}$} & $1 d$ & $41(35-47)$ & $82(76-87)$ \\
\hline & $2 d$ & $38(37-40)$ & $76(72-80)$ \\
\hline & $3 d$ & $31(29-34)$ & $65(60-69)$ \\
\hline \multirow[t]{3}{*}{$\mathrm{UA}, \mu \mathrm{mol} / \mathrm{L}$} & $1 d$ & $99(68-151)$ & $454(388-512)$ \\
\hline & $2 d$ & $97(87-110)$ & $335(318-351)$ \\
\hline & $3 d$ & 78 (69-88) & $271(236-300)$ \\
\hline \multicolumn{4}{|l|}{ Enzymes } \\
\hline$A L T, U / L$ & $1-3 d$ & $6^{\mathrm{a}}$ & $44(41-46)$ \\
\hline$A L P, U / L$ & $1-3 d$ & $91(83-103)$ & $229(214-240)$ \\
\hline AST, U/L & $1-3 d$ & $29(29-33)$ & $101(92-115)$ \\
\hline $\mathrm{CHE}, \mathrm{U} / \mathrm{L}$ & $1-3 d$ & 3299 (3272-3397) & 6491 (5838-6736) \\
\hline GGT, U/L & $1-3 d$ & $42(39-54)$ & $302(280-316)$ \\
\hline CK, U/L & $1-3 d$ & $95(89-109)$ & 715 (566-773) \\
\hline CK-MB, U/L & $1-3 d$ & $12(11-13)$ & $40(39-41)$ \\
\hline $\mathrm{LDH}, \mathrm{U} / \mathrm{L}$ & $1-3 d$ & $651(570-720)$ & 1577 (1524-1620) \\
\hline \multicolumn{4}{|l|}{ Proteins } \\
\hline Alb, g/L & $1-3 d$ & $28(27-28)$ & $40(39-43)$ \\
\hline$T P, g / L$ & $1-3 d$ & $41(40-41)$ & $59(57-61)$ \\
\hline \multicolumn{4}{|l|}{ Lipids/Lipoproteins } \\
\hline $\mathrm{HDL}-\mathrm{C}, \mathrm{mmol} / \mathrm{L}$ & $1-3 d$ & $0.43(0.39-0.46)$ & $1.13(1.04-1.19)$ \\
\hline $\mathrm{LDL}-\mathrm{C}, \mathrm{mmol} / \mathrm{L}$ & $1-3 d$ & $0.20(0.17-0.22)$ & $1.48(1.26-1.76)$ \\
\hline \multirow[t]{2}{*}{$\mathrm{TCHO}, \mathrm{mmol} / \mathrm{L}$} & $1-2 d$ & $1.29^{\mathrm{a}}$ & $2.57(2.46-3.11)$ \\
\hline & $3 d$ & $1.29^{\mathrm{a}}$ & $3.16(2.96-3.37)$ \\
\hline \multirow[t]{2}{*}{$\mathrm{TG}, \mathrm{mmol} / \mathrm{L}$} & $1-2 d$ & $0.38(0.33-0.43)$ & $1.25(1.12-1.55)$ \\
\hline & $3 d$ & $0.32(0.22-0.44)$ & $1.84(1.66-2.01)$ \\
\hline
\end{tabular}

a Lowest detection limit. Actual values could be lower 
Table 4 Multiple linear regression of individual characteristics on the biochemical analytes

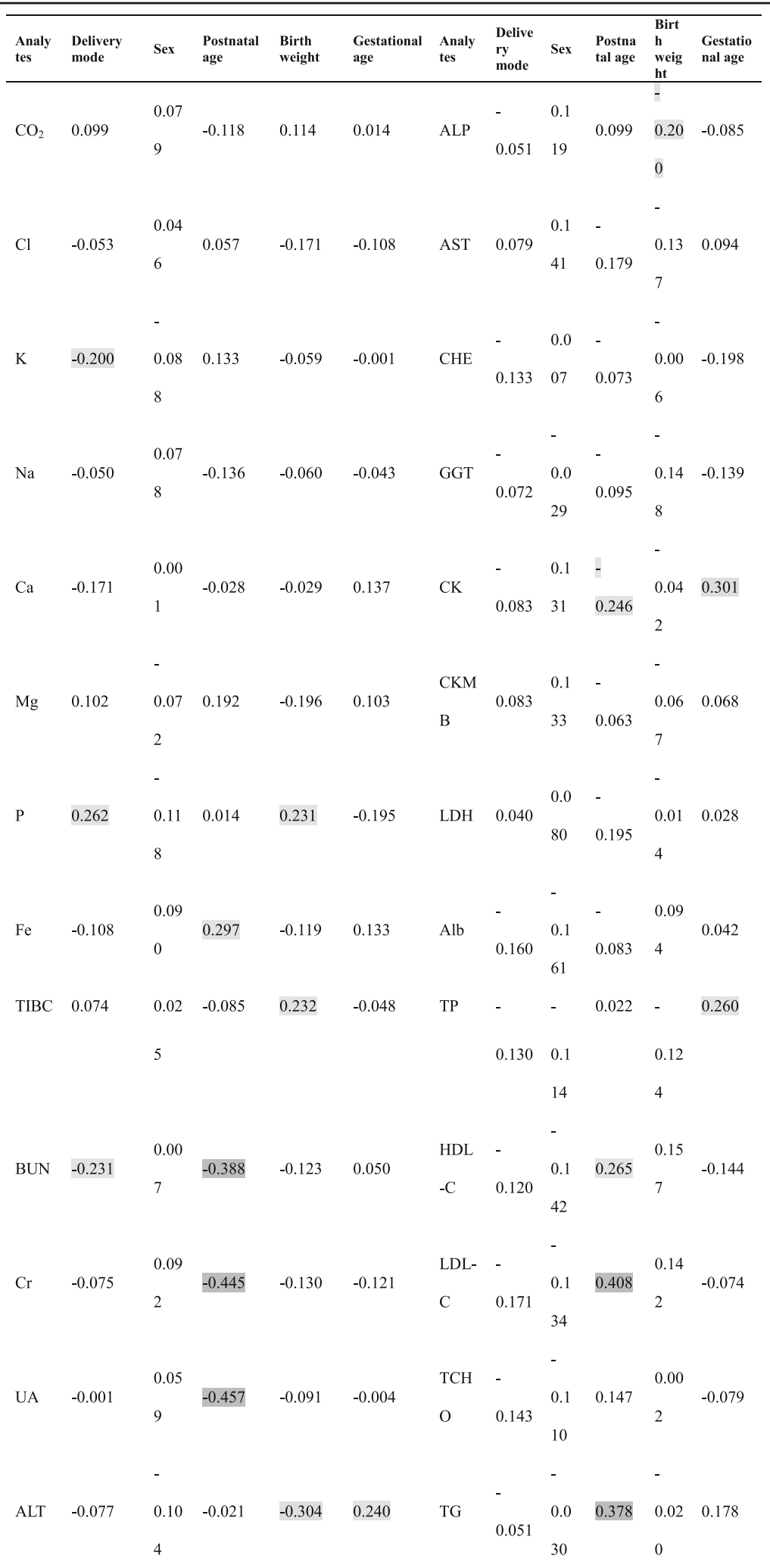

Listed values are standardized partial regression coefficients $\left(r_{p}\right)$. $\left|r_{p}\right|$ values that exceed 0.2 was shown in three graded black background colors: light $0.2 \leq\left|r_{p}\right|<$ 0.3 , moderate $0.3 \leq\left|r_{p}\right| \leq 0.5$, dark $\left|r_{p}\right| \geq 0.5$ respectively 


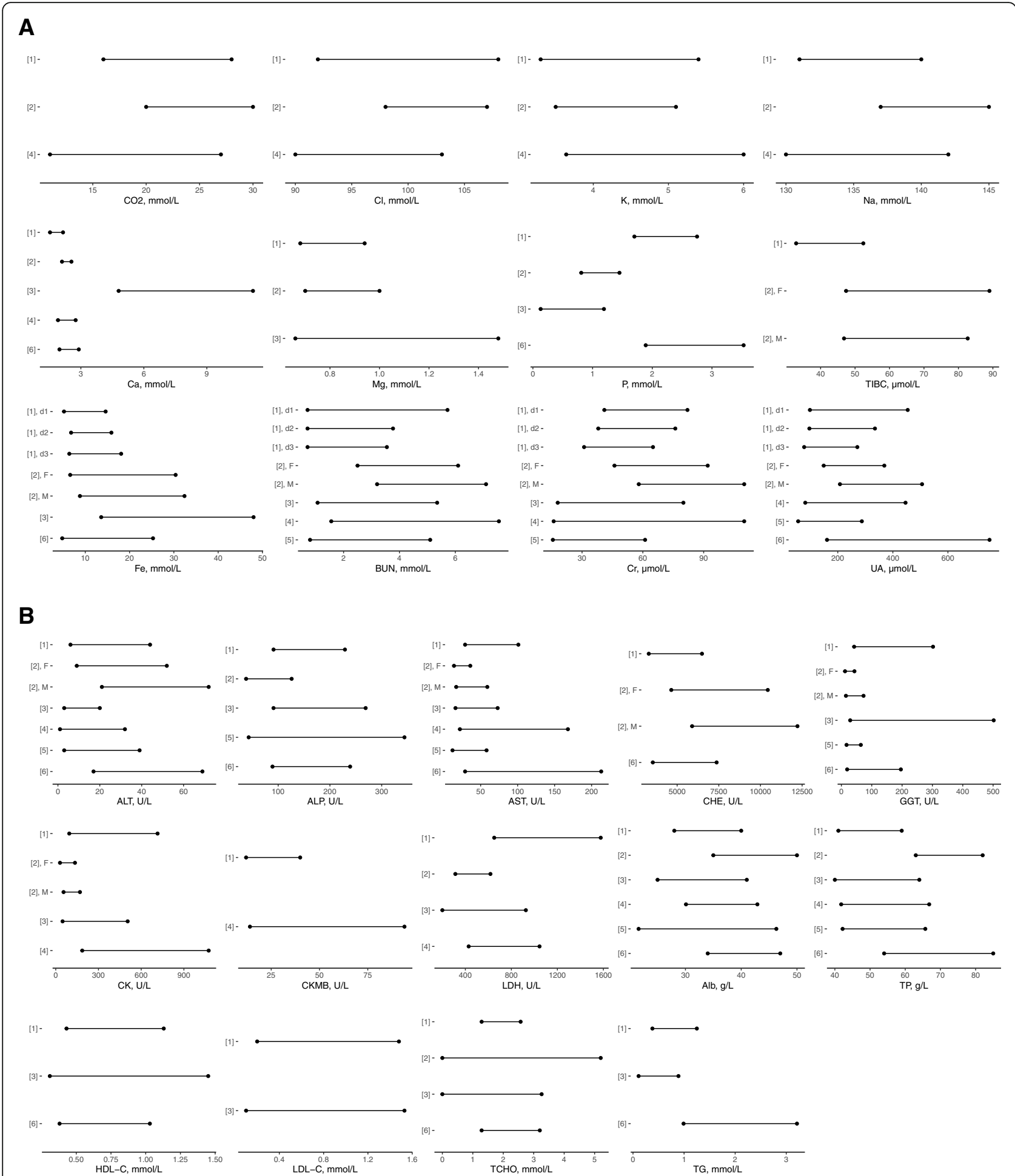

Fig. 3 Biochemical reference intervals in comparison with other studies. [1] represents the current study, [2] represents kit insert ( $F$ for female, M for male), [3] represents Choi et al., [4] represents Zhao et al., [5] represents Liu et al., [6] represents Higgins et al 
of their metabolism in advanced pregnancy [19, 38]. It is noteworthy that the expression of LC3-II and p62 in cord blood was associated with serum total protein in infants, perhaps suggesting that the autophagy reaction introduced by postnatal starvation played a crucial part in the maintenance of protein or amino acid metabolism during the perinatal period [39].

\section{Comparison to other studies}

RIs in our study were compared with those of kit inserts and other studies, which covered different experimental types and designs, assay systems, characteristics of the studied population and specimen types. The manufacturer RIs were less reliable in the evaluation of clinical applicability before use in Chinese laboratories, because they were generally based on Caucasian people and lacked data on children. The RIs of $\mathrm{Cl}, \mathrm{K}$ and $\mathrm{Na}$ were similar to those from reagent inserts and previous findings for children and adolescents [8]. Therefore, it seemed that the three electrolytes remained relatively stable in one's life. The differences of RIs for $\mathrm{Ca}, \mathrm{Mg}, \mathrm{P}$ and lipids between this study and a study in Korea, to some extent, might be explained by the fact that umbilical cord contained maternal substances for fetal development. Compared to another two studies in other parts of China, there might be some factors that contributed to the differences between RIs, including actual differences between cities, laboratories, analytical systems and statistical calculation methods reported in these studies. Moreover, Liu et al. [26] used an indirect method for determination of RIs, which based on the stricter exclusion criteria and wider age intervals, and then little data about the rapid changes was presented during the first days.

As mentioned in the Caliper's report about transferred RIs from Abbott to Ortho assays [40], $\mathrm{Ca}, \mathrm{CO}_{2}, \mathrm{Mg}$ and LDH did not meet transference or verification criteria. Except these, the RIs of most corresponding analytes showed higher values, which might be attributed to racial and diet differences. This finding further support that laboratories should verify transferred RIs for local population and analytical platform-that covers as many partitioned RIs as possible-according to CLSI guidelines.

\section{Limitations}

Unfortunately, several limitations existed. The current work was based on a small sampling of healthy newborns, and the distribution of data was unbalanced between subgroups. All the subjects contained a high number of neonates on the 2nd day and by caesarean section. Once the RI was partitioned, the small sample size would be hard to assure a highly accurate RI with narrow confidence intervals. Furthermore, this study just determined the RIs in newborns aged $0-3$ days, and new data on infant period should be supplemented in the future. All the analytes should be evaluated on their validity of routine use in clinics and further investigated in preterm infants. The percentile charts provided might be integrated into the hospital and laboratory information system to implement new strategies for result display.

\section{Conclusion}

This study used a priori method to investigate analyzer and reagent-appropriate RIs in term infants, with clear inclusion and exclusion criteria, standardized sample processing procedures and novel data analysis methods. Moreover, the research of establishing RIs on VITROS 5600 Integrated System was unique, and this study complemented those of earlier studies on children and adolescents. In summary, this study preliminarily established serum RIs for 26 common biochemical analytes in healthy term infants, investigated their dynamic changes during the first 3 days of life and evaluated the associations of individual characteristics with these analytes. The results of this study indicated that day-age-appropriate RIs should be considered for newborns in the field of perinatal-neonatal medicine. Continued efforts are needed to further assess the significance of these RIs in routine clinical work and disease diagnosis.

\section{Supplementary Information}

The online version contains supplementary material available at https://doi. org/10.1186/s12887-021-02565-8.

Additional file 1: Supplemental Table 1. Analytical performance of chemistry assays on the Ortho VITROS 5600 Integrated System.

Additional file 2. Percentile charts and combined Rls for other biochemical analytes.

Additional file 3: Supplemental Table 2. Summary of reference intervals for 26 biochemistry analytes in comparison with other studies.

\section{Abbreviations}

$\mathrm{CO}_{2}$ : Total carbon dioxide; Cl: Chloride; K: Potassium; Na: Sodium; Ca: Calcium; Fe: Iron; Mg: Magnesium; P: Phosphorus; Cr: Creatinine; BUN: Urea; UA: Uric acid; ALT: Alanine aminotransferase; ALP: Alkaline phosphatase; AST: Aspartate aminotransferase; CHE: Cholinesterase; CK: Creatine kinase; CK-MB: Creatine kinase MB form; GGT: Gamma glutamyl transferase; LDH: Lactate dehydrogenase; Alb: Albumin; TP: Total protein; TIBC: Transferrin iron-binding capacity; HDL-C: High-density lipoproteincholesterol; TCHO: Cholesterol; TG: Triglycerides; LDL-C: Low-density lipoprotein-cholesterol; LL: Lower limit; MRA: Multiple regression analysis; UL: Upper limit; SDR: Standard deviations ratio; $r_{p}$ : Partial correlation coefficient; Rl: Reference interval

Acknowledgements

Acknowledgement is given to all the participants and their families.

Authors' contributions

WKJ gathered and analysed the data, and wrote the first draft of the manuscript. ZXT was involved in gaining ethical approval, patient recruitment and experimental operation. ZQ and XJC conceived the study and contributed to protocol development. XJC revised the article. All authors have reviewed and edited the manuscript and approved the final version of the manuscript. 


\section{Funding}

This work was supported by the Jilin Science and Technology Development Program [grant numbers 20170623092TC-09, 20190304110YY] and the First Hospital Translational Funding for Scientific \& Technological Achievements [grant number JDYYZH-1902002].

\section{Availability of data and materials}

The datasets used and/or analysed during the current study are available from the corresponding author on reasonable request.

\section{Declarations}

\section{Ethics approval and consent to participate}

The study protocol was approved by the Ethics Committee of the First Hospital of Jilin University. All procedures performed in this study were in accordance with the ethical standards of the Ethics Committee of the First Hospital of Jilin University (reference number: 2016-306), as well as the 1964 Helsinki declaration and its subsequent amendments or comparable ethical standard. Written informed consent was obtained from all parents for the participants included in the study.

\section{Consent for publication}

N/A.

\section{Competing interests}

The authors declare that they have no competing interests.

\section{Author details}

${ }^{1}$ Department of Laboratory Medicine, First Hospital of Jilin University, Changchun, China. '2Department of Pediatrics, First Hospital of Jilin University, Changchun, China.

Received: 21 November 2020 Accepted: 18 February 2021 Published online: 31 March 2021

\section{References}

1. Ichihara K, Itoh Y, Lam CW, Poon PM, Kim JH, Kyono H, Chandrawening N, Muliaty D. Sources of variation of commonly measured serum analytes in 6 Asian cities and consideration of common reference intervals. Clin Chem. 2008;54(2):356-65

2. Xia L, Chen M, Liu M, Tao Z, Li S, Wang L, Cheng X, Qin X, Han J, Li P, et al. Nationwide multicenter reference interval study for 28 common biochemical Analytes in China. Medicine (Baltimore). 2016;95(9):e2915.

3. Adeli K, Higgins V, Trajcevski K, White-Al Habeeb N. The Canadian laboratory initiative on pediatric reference intervals: a CALIPER white paper. Crit Rev Clin Lab Sci. 2017;54(6):358-413.

4. Hoq M, Matthews S, Karlaftis V, Burgess J, Cowley J, Donath S, Carlin J, Yen $T$, Ignjatovic $V$, Monagle $P$, et al. Reference values for 30 common biochemistry Analytes across 5 different analyzers in neonates and children 30 days to 18 years of age. Clin Chem. 2019:65(10):1317-26.

5. Zierk J, Arzideh F, Rechenauer T, Haeckel R, Rascher W, Metzler M, Rauh M. Age- and sex-specific dynamics in 22 hematologic and biochemical Analytes from birth to adolescence. Clin Chem. 2015;61(7):964-73.

6. Guo W, Zhou Q, Jia Y, Xu J. Age- and sex-specific reference intervals for myocardial enzyme activity in healthy Chinese Han population aged 1 approximately <18 years. Biomed Res Int. 2019;2019:2018598.

7. Guo W, Zhou Q, Jia Y, Xu J. Division of myocardial enzyme reference intervals in population aged 1 to $<18$ years old based on Fisher's optimal segmentation method. Comput Math Methods Med. 2020:2020:2013148.

8. Zhu X, Wang K, Zhou Q, Guo W, Jia Y, Xu J. Age- and sex-specific pediatric reference intervals of serum electrolytes in Jilin Province of China using the a priori approach. Am J Clin Pathol. 2020;154(5):708-20.

9. Zhu X, Wang K, Zhou Q, Xu J. Establishment of age- and sex-specific reference intervals for serum liver function tests in pediatric population aged 1-<18 years: A prospective study. J Clin Lab Anal. 2021:e23708. https:// doi.org/10.1002/jcla.23708. Online ahead of print.

10. lanni B, McDaniel H, Savilo E, Wade C, Micetic B, Johnson S, Gerkin R. Defining Normal healthy term newborn automated hematologic reference intervals at 24 hours of life. Arch Pathol Lab Med. 2021;145(1):66-74.

11. Schmidt BM, Tameris M, Geldenhuys H, Luabeya A, Bunyasi E, Hawkridge T, McClain JB, Mahomed H, Scriba TJ, McShane H, et al. Comparison of haematology and biochemistry parameters in healthy south African infants with laboratory reference intervals. Tropical Med Int Health. 2018;23(1):63-8.

12. Moyer-Mileur $L$. Anthropometric and laboratory assessment of very low birth weight infants: the most helpful measurements and why. Semin Perinatol. 2007;31(2):96-103.

13. Choi SJ, Lee S, Lee B, Jang JY, Cho J, Uh Y. Comparison of neonatal reference intervals for 23 biochemical analytes in the cord blood-a single center study in South Korea. Turk J Pediatr. 2019;61(3):337-44.

14. Ochiai M, Matsushita Y, Inoue H, Kusuda T, Kang D, Ichihara K, Nakashima N, Ihara K, Ohga S, Hara T, et al. Blood reference intervals for preterm lowbirth-weight infants: a multicenter cohort study in Japan. PLoS One. 2016; 11(8):e0161439.

15. Zhao $\mathrm{C}$, Wang $\mathrm{H}$, Zhang $\mathrm{C}, \mathrm{He} \mathrm{L}$. Research on reference values of 26 items of serum biochemical parameters in Lanzhou healthy neonates. Int J Lab Med. 2007:28(3):211-3.

16. Institute CaLS. Defining, Establishing, and Verifying Reference Intervals in the Clinical Laboratory; Approved Guideline-3rd ed. CLSI document C28-A3c. Wayne: Institute CaLS; 2010.

17. Dokos C, Tsakalidis C, Manaridou K, Karayianni P, Kyrkos I, Roussos I. Clinicallaboratory findings of bone metabolism in healthy premature and full-term neonates: preliminary results. Clin Cases Miner Bone Metab. 2017;14(2):167-72.

18. Donega S, Oba J, Maranhao RC. Concentration of serum lipids and apolipoprotein B in newborns. Arq Bras Cardiol. 2006:86(6):419-24.

19. Elizabeth KE, Krishnan V, Zachariah P. Auxologic, biochemical and clinical $(A B C)$ profile of low birth weight babies- a 2-year prospective study. J Trop Pediatr. 2007;53(6):374-82.

20. Yee TW. Vector generalized linear and additive models: with an implementation in R: springer; 2015.

21. Yee TW. Wild CJJotRSSSB: Vector generalized additive models. J R Stat Soc Series B Stat Methodol. 1996;58(3):481-93.

22. Ichihara K, Boyd JC, Intervals ICOR, Decision L. An appraisal of statistical procedures used in derivation of reference intervals. Clin Chem Lab Med. 2010:48(11):1537-51.

23. Shah SAV, Ichihara K, Dherai AJ, Ashavaid TF. Reference intervals for 33 biochemical analytes in healthy Indian population: C-RIDL IFCC initiative. Clin Chem Lab Med. 2018;56(12):2093-103.

24. Borai A, Ichihara K, Masaud A, Tamimi W, Bahijri S, Armbuster D, Kawano R, Baarmah Z, Joatar F, Almohammadi M. Establishment of reference intervals for immunoassay analytes of adult population in Saudi Arabia. Clin Chem Lab Med. 2020;58(8):1302-13.

25. Evgina S, Ichihara K, Ruzhanskaya A, Skibo I, Vybornova N, Vasiliev A, Kimura S, Butlitski D, Volkova E, Vilenskaya E, et al. Establishing reference intervals for major biochemical analytes for the Russian population: a research conducted as a part of the IFCC global study on reference values. Clin Biochem. 2020;81:47-58

26. Liu J, Dai Y, Lee Y, Yuan E, Wang Q, Wang L, Su Y. Pediatric reference intervals of liver and renal function tests from birth to adolescence in Chinese children as performed on the Olympus AU5400. Clin Chim Acta. 2019:490:142-6.

27. Cheng YW, Kaimal AJ, Bruckner TA, Halloran DR, Caughey AB. Perinatal morbidity associated with late preterm deliveries compared with deliveries between 37 and 40 weeks of gestation. BJOG. 2011;118(12):1446-54.

28. Ichihara K, Yomamoto $Y$, Hotta T, Hosogaya S, Miyachi H, Itoh Y, Ishibashi M, Kang D, Committee on Common Reference Intervals JSoCC. Collaborative derivation of reference intervals for major clinical laboratory tests in Japan. Ann Clin Biochem. 2016;53(Pt 3):347-56.

29. Yip PM, Chan MK, Nelken J, Lepage N, Brotea G, Adeli K. Pediatric reference intervals for lipids and apolipoproteins on the VITROS 5,1 FS chemistry system. Clin Biochem. 2006:39(10):978-83.

30. Novo AC, Sadeck Ldos S, Okay TS, Leone CR. Longitudinal study of Cystatin $C$ in healthy term newborns. Clinics (Sao Paulo). 2011:66(2):217-20.

31. Lackmann GM. Reference values for selected enzyme activities in serum from healthy human neonates. Clin Biochem. 1996;29(6):599-602.

32. Nakajima J, Tsutsumi N, Nara S, Ishii H, Suganami Y, Sunohara D, Kawashima $\mathrm{H}$. Correlations of enzyme levels at birth in stressed neonates with shortterm outcomes. Fetal Pediatr Pathol. 2018:37(3):157-65.

33. Larque E, Morales E, Leis R, Blanco-Carnero JE. Maternal and Foetal health implications of vitamin D status during pregnancy. Ann Nutr Metab. 2018;72(3):179-92.

34. Sethi A, Priyadarshi M, Agarwal R. Mineral and bone physiology in the foetus, preterm and full-term neonates. Semin Fetal Neonatal Med. 2020;25(1):101076.

35. Liu JX, Au Yeung SL, Kwok MK, Leung JYY, Lin SL, Hui LL, Leung GM, Schooling CM. Birth weight, gestational age and late adolescent liver 
function using twin status as instrumental variable in a Hong Kong Chinese birth cohort: "children of 1997". Prev Med. 2018;111:190-7.

36. Fraser A, Ebrahim S, Smith GD, Lawlor DA. The associations between birthweight and adult markers of liver damage and function. Paediatr Perinat Epidemiol. 2008;22(1):12-21

37. Chen S, Guo X, Yu S, Zhou Y, Li Z, Sun Y. Metabolic syndrome and serum liver enzymes in the general Chinese population. Int J Environ Res Public Health. 2016;13(2):223.

38. Bellieni CV, Tomasini B, Bracciali C, Buonocore G. Normal values of creatine kinase and of MB-creatine kinase at birth in healthy babies. Minerva Pediatr. 2017. https://doi.org/10.23736/50026-4946.17.04852-6. Online ahead of print.

39. Sekiguchi K, Miyahara H, Inoue M, Maeda T, Ihara K. The autophagy reaction in the human umbilical cord: a potential marker for estimating fetal nutrition and neonatal growth. J Matern Fetal Neonatal Med. 2020:1-5. https://doi.org/10.1080/14767058.2020.1730320. Online ahead of print.

40. Higgins V, Truong D, Woroch A, Chan MK, Tahmasebi H, Adeli K. CLSI-based transference and verification of CALIPER pediatric reference intervals for 29 Ortho VITROS 5600 chemistry assays. Clin Biochem. 2018;53:93-103.

\section{Publisher's Note}

Springer Nature remains neutral with regard to jurisdictional claims in published maps and institutional affiliations.

Ready to submit your research? Choose BMC and benefit from:

- fast, convenient online submission

- thorough peer review by experienced researchers in your field

- rapid publication on acceptance

- support for research data, including large and complex data types

- gold Open Access which fosters wider collaboration and increased citations

- maximum visibility for your research: over $100 \mathrm{M}$ website views per year

At BMC, research is always in progress.

Learn more biomedcentral.com/submissions 